\title{
Percutaneous vertebroplasty and interventional tumor removal for malignant vertebral compression fractures and/or spinal metastatic tumor with epidural involvement: a prospective pilot study
}

This article was published in the following Dove Press journal: Journal of Pain Research

20 January 2017

Number of times this article has been viewed

\section{Yi-Feng Gu' \\ Qing-Hua Tian' \\ Yong-Dong $\mathrm{Li}^{\prime}$ \\ Chun-Gen Wu' \\ Yan $\mathrm{Su}^{2}$ \\ Hong-Mei Song \\ Cheng-Jian $\mathrm{He}^{\prime}$ \\ Dong Chen ${ }^{2}$}

'Institute of Diagnostic and Interventional Radiology, ${ }^{2}$ Department of Orthopaedics, Shanghai Jiao Tong University Affiliated Sixth People's Hospital, Shanghai, People's Republic of China
Correspondence: Chun-Gen Wu; Yan Su Institute of Diagnostic and Interventional Radiology; Department of Orthopaedics, Shanghai Jiao Tong University Affiliated Sixth People's Hospital, No 600, Yi Shan Road, Shanghai 200233, People's Republic of China

Tel +862164834183

Fax +862164844183

Emailwucgsh@I63.com; yansualex@I63. com
Objective: The aim of this study was to compare the efficacy of percutaneous vertebroplasty (PVP) and interventional tumor removal (ITR), with PVP alone for malignant vertebral compression fractures and/or spinal metastatic tumor with epidural involvement.

Patients and methods: A total of 124 patients were selected for PVP and ITR ( $\mathrm{n}=71$, group A) and PVP alone ( $\mathrm{n}=53$, group B). A $14 \mathrm{G}$ needle and guide wire were inserted into the vertebral body, followed by sequential dilatation of the tract until the last cannula reached the anterior portion of the pedicle. Tumors were then ablated with a radiofrequency probe. ITR was performed with marrow nucleus rongeurs, and then cement was injected into the extirpated vertebra. Outcomes were collected preoperatively and at 1, 3 and 6 months and every subsequent 6 months.

Results: The rates of pain relief and increased mobility at the last follow-up were higher in group A than those in group B $(P<0.05)$. There were significant differences in visual analog scale (VAS) score and Oswestry disability index (ODI) score at 1, 3 and 6 months, 1 year and $>1$ year in group A than in group $\mathrm{B}(P<0.05)$. The rates of paraplegia recovery and vertebral stability in group A were higher than those in group B $(P<0.05)$.

Conclusion: PVP and ITR proved to be an effective approach for patients with malignant vertebral compression fractures and/or spinal metastatic tumor and provided distinct advantages in pain relief, function recovery and vertebral stability that are comparable to that obtained with PVP alone.

Keywords: percutaneous vertebroplasty, pain, malignant spinal tumor, removal, metastasis

\section{Introduction}

Percutaneous vertebroplasty (PVP) has been highly effective in reducing spinal pain in osteoporotic vertebral compression fractures and vertebral metastatic disease. ${ }^{1-10}$ In addition, this procedure may have shorter operative times, less blood loss, less postoperative pain and a lower overall cost. ${ }^{11}$ However, the major complications of this procedure include cement leakage into the canal or nerve root foramen resulting in spinal cord compression or radiculopathy, etc.

In addition, in many conditions, tumor burden is severe and PVP alone could not achieve complete pain relief and vertebral stability. These conditions include the following: 1) patients with massive polymethyl methacrylate (PMMA) leakage, 2) patients 
with destruction of the posterior cortex of the vertebral body, and 3) patients with malignant vertebral compression fractures. Thus, PVP is often not a good option for these patients. So, we accepted a new approach - interventional tumor removal (ITR), that is to say, we used PVP and ITR for pain relief or vertebral stabilization during one session. ${ }^{12-14}$ The purpose of this study was to compare the efficacy of PVP and ITR with PVP alone for malignant vertebral compression fractures and/ or spinal metastatic tumor with epidural involvement.

\section{Patients and methods Study design}

This study (Level IV) was approved by the Ethics Committee of Shanghai Sixth People's Hospital, and written informed consent was obtained from each patient. From October 2009 to December 2015, patients with malignant vertebral compression fractures and/or spinal metastatic tumor with epidural involvement were allocated to PVP and ITR (group A) and PVP alone (group B) treatment. Diagnoses were confirmed by reviewing the patients' history and findings on computed tomography (CT) and magnetic resonance imaging (MRI).

Patients' inclusion criteria include: the patients with 1) malignant vertebral compression fractures and/or spinal metastatic tumor with epidural involvement (broken in the posterior cortex on MRI imaging) caused by metastases; 2) intractable pain; 3) unresponsive to nonoperative modalities, such as radiation therapy and chemotherapy; 4) a confirmed histological diagnosis; 5) the percentage of height reduction in vertebral body $<50 \%$ and 6 ) who had one clinical and MRI follow-up $\geq 3$ months after the initial treatment. Exclusion criteria include allergy to PMMA, poor overall condition and short life expectancy ( $<3$ months). All patients underwent anteroposterior (AP) and lateral radiograph and CT scan, which were performed to evaluate the fracture configuration and vertebral wall integrity before the procedure. Marrow signal changes on MRI were assessed to determine the symptomatic levels and acuity of the fractures.

\section{Interventional procedures}

All the procedures were performed by two experienced interventional radiologists (YFG and CGW, with 8 and 5 years of experience in spinal intervention, respectively) on a monoplanar unit (Axiom Artis VB22N; Siemens, Berlin, Gremany).

\section{PVP and ITR}

The technique steps and interventional procedures have been described previously. ${ }^{12-14}$ The patient was placed in a prone position on an operating table. After marking the skin $5 \mathrm{~cm}$ from the midline, the skin entry point and tract were selected under fluoroscopic guidance and infiltrated. After local anesthesia ( $2 \%$ lidocaine), a small incision was made with a scalpel blade. With intermittent fluoroscopic monitoring, a $14 \mathrm{G}$ needle and guide wire were inserted at the site of entry until the tip reached the center of the vertebral body, followed by sequential dilatation of the tract with working cannulae (Dragon-Crown Co, Jinan, China) until the last working cannula (5 $\mathrm{mm}$ in diameter) reached the anterior portions of the pedicle. After removal of the final cannula (Dragon-Crown Co), a trephine was inserted through the last working cannula and the pedicle of the vertebral arch was cut slowly until the last working cannula reached the anterior portions of the pedicle.

After the removal of the guide wire and trephine, ITR was performed with marrow nucleus rongeurs (DragonCrown Co) inserted through the working cannula. The ITR was extended more deeply into the involved level so that more tumor tissue could be removed from the vertebral body. Approximately $5-10 \mathrm{~mL}$ of commercially available PMMA (Osteo-Firm; COOK Medical, Bloomington, IN, USA) was then carefully injected into the treated vertebral body under intermittent fluoroscopic monitoring of AP and lateral projections to ensure adequate filling of the lesion and to avoid leakage or migration of PMMA into the venous system toward the lungs. Injection was ceased when substantial resistance was met or when the cement reached the posterior cortex edge of the broken vertebral body; injection was also immediately stopped if cement leaked into extraosseous structures, epidura foramen or veins. Immediately after the procedure, standard AP and lateral radiographs were obtained. After the procedure, patients were monitored for up to 6 hours postoperatively.

\section{PVP procedure}

The patient was placed in a prone position on an operating table. After local anesthesia, a small incision was made with a scalpel blade. Thereafter, a $13 \mathrm{G}$ bone puncture needle (COOK Medical) was placed transpedicularly in the fractured vertebral body. After the removal of the inner needle, commercially available PMMA (COOK Medical) was carefully injected into the fractured vertebral body under intermittent fluoroscopic monitoring via AP and lateral projections in order to ensure adequate lesion filling. Injection was ceased when substantial resistance was met or when the cement reached the cortical edge of the fractured vertebral body. 


\section{Clinical outcome evaluation}

Patients were clinically examined by two of the authors (HMS and $\mathrm{CJH}$ ), who gathered initial and follow-up data before the procedure and 1, 3 and 6 months and every subsequent 6 months thereafter. In cases where clinical examination could not be performed, patients or their family were contacted by telephone every 3 months. Imaging follow-up comprised AP and lateral spinal radiography at 1 month, 6 months and 1 year after the procedure. CT of the treated vertebra was conducted 3 days after PVP with $2 \mathrm{~mm}$ slices to determine the distribution of cement in the lesion and to look for cement leakage outside the vertebral body or other possible local complications. CT and/or MRI was performed in the same manner as before the procedure at 3 months and every 6 months after the procedure in all patients.

Data regarding the technical success, pain relief, functional outcomes, paraplegia and complications were evaluated at follow-up consultations or at patient death. All the data were obtained prospectively by the completion of clinical surveys by the authors. Technical success was defined as the successful puncture of the pedicle of the vertebral arch, the sequential dilatation of the tract with a working cannula ITR and PVP without any major complications.

The pain relief was measured by a visual analog scale (VAS) score ranging from 0 to 10 and categorized into four types: excellent result (0-2), good result (2.5-4.5), fair and poor. The functional status of patients for walking, standing and sleeping was measured by the Oswestry disability index (ODI) questionnaire. The functional outcomes were measured on a 100-point Karnofsky performance scale (KPS) to assess the changes in the quality of life.

The paraplegia was assessed using American Spinal Injury Association (ASIA) impairment scale and categorized into five types from A to E. ${ }^{15}$ Complete paraplegia was defined as ASIA impairment scale A, incomplete paraplegia was defined as ASIA impairment scale B-D and no paraplegia was defined as ASIA impairment scale E. We defined clinical improvement of paraplegia as a decrease in ASIA impairment scale from baseline of 1 point or more. Full recovery from paraplegia was defined as days with ASIA impairment scale of E.

Any potential complications following PVP, such as wound infections, nerve injuries, cement leakage and pulmonary embolism, were recorded.

\section{Statistical analysis}

Descriptive data were given as the mean \pm SD. Dichotomous and categorical data were reported as numbers and percentages. Comparisons of the variables between the two groups were performed by applying the Mann-Whitney test, $\chi^{2}$-test or the Fisher's exact test as appropriate. All statistical analyses were performed using the SPSS package, version 13.0 (SPSS, Chicago, IL, USA).

\section{Results}

A total of 145 consecutive patients were enrolled in this study. Before each procedure, patients or family members were given a choice of PVP and ITR or PVP alone. Initially, the study population consisted of 81 patients in the PVP and ITR group (group A; Figures 1 and 2) and 64 patients in the PVP group (group B; Figure 3). Of these, 21 patients did not meet the inclusion criteria, without follow-up MRI in 13 patients (seven in group A and six in group B) and follow-up loss in eight patients (three in group A and five in group B). So, a final total of 71 and 53 patients were included in group A and group $\mathrm{B}$, respectively. Baseline characteristics of the 124 patients between the two groups are summarized in Table 1 .

ASIA impairment scale assessment prior to the procedure exhibited ASIA impairment scale E (no paraplegia) in
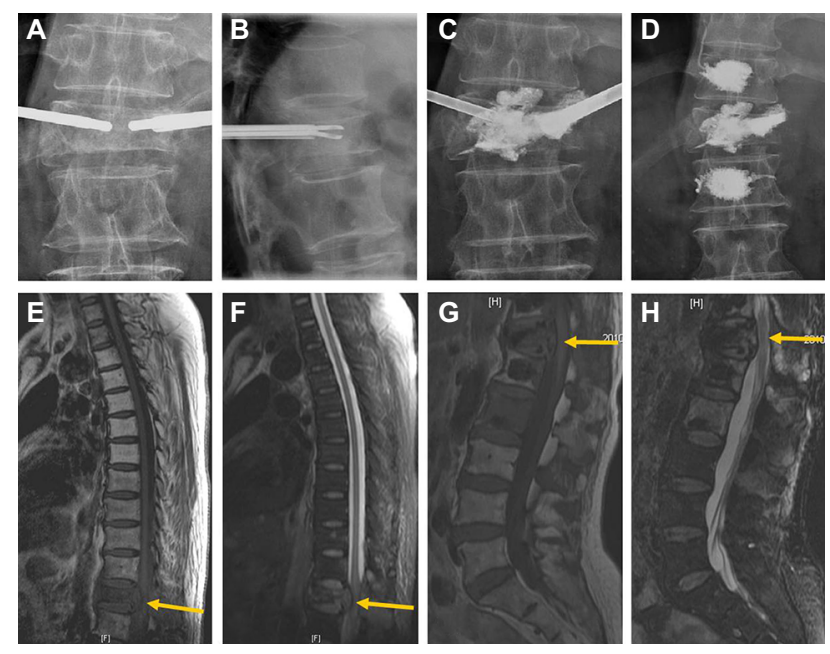

Figure I Group A Spinal metastatic tumor with epidural involvement of TI2 vertebra owing to metastasis from lung cancer in a 67-year-old female patient with spinal pain prior to the procedure.

Notes: (A, B) The last working cannulae is inserted into vertebral body from the both side, and ITR is performed with a marrow nucleus rongeurs inserted through the working cannula from the right side. (C) AP shows the PMMA is injected into the TI 2 vertebral body with paravertebral space and intervertebral disk leakage. (D) AP shows the PMMA is injected into the TII, TI2 and LI vertebral body after the procedures. (E, F) Sagittal TIWI and T2WI show spinal metastatic tumor with spinal cord compression of TI2 vertebra (arrow) prior to the procedure. (G, H) Sagittal TIWI and T2WI reveals low signal at TI2 vertebral body (arrow) with stability of the vertebral body 6 months after PVP and ITR. Note the spinal cord compression is relieved and the spinal pain is resolved after the procedure.

Abbreviations: AP, anteroposterior; PMMA, polymethyl methacrylate; PVP, percutaneous vertebroplasty; ITR, interventional tumor removal; TIWI, TIweighted image; T2WI, T2-weighted image. 


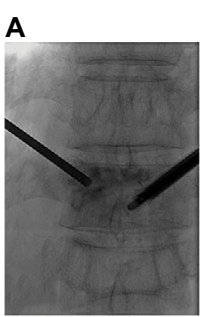

E
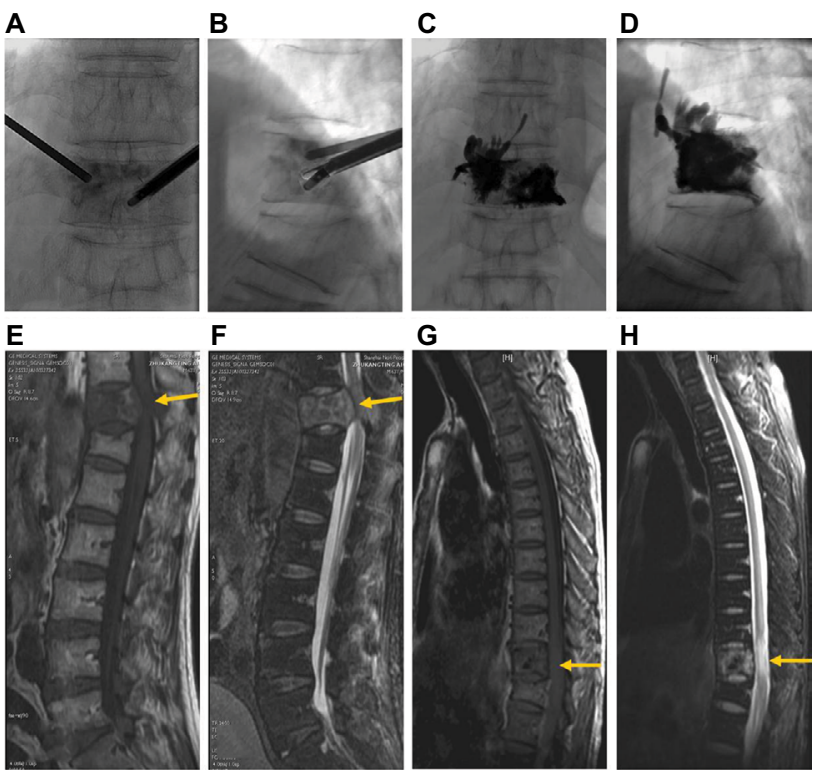

$\mathbf{F}$
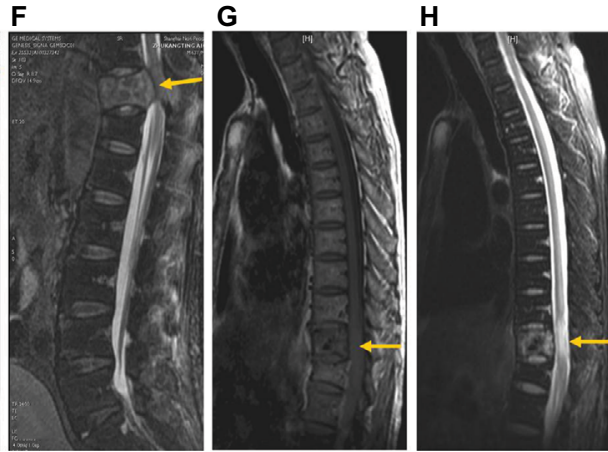

Figure 2 Group A: malignant vertebral compression fracture of TII vertebra owing to metastasis from prostate cancer in a 63-year-old male patient with spinal pain and symptom of neurologic compression prior to the procedure.

Notes: (A, B) The AP and lateral view show that ITR is performed with a marrow nucleus rongeurs inserted through the working cannula from the left side. (C, D) The AP and lateral view show that the PMMA is injected into the TII vertebral body with paravertebral space and vein leakage. (E, F) Sagittal TIWI and T2WI show malignant vertebral compression fractures of TII vertebra (arrow) with spinal cord compression and rupture of posterior wall prior to the procedure. (G, H) Sagittal TIWI and T2WI reveal low signal at TII vertebral body (arrow) with stability of the vertebral body 5 months after ITR and PVP. Note the spinal cord compression is relieved and the spinal pain is resolved after the procedure.

Abbreviations: AP, anteroposterior; ITR, interventional tumor removal; PVP, percutaneous vertebroplasty; PMMA, polymethyl methacrylate; TIWI, TI-weighted image; T2WI, T2-weighted image.

40 patients, ASIA impairment scale A (complete paraplegia) in three patients and ASIA impairment scale B-D (incomplete paraplegia) in 28 patients in group A. ASIA impairment scale assessment prior to the procedure exhibited ASIA impairment scale $\mathrm{E}$ (no paraplegia) in 25 patients, ASIA impairment scale A (complete paraplegia) in one patient and ASIA impairment scale B-D (incomplete paraplegia) in 27 patients in group B.

\section{Safety}

The technical and initial clinical outcomes of the two groups are shown in Table 2. In group A, PVP and ITR were technically successful in all patients except one with incomplete paraplegia due to arrhythmia during the procedures giving a technical successful rate of $98.6 \%$ (95\% confidence interval [95\% CI]: 96\%, 101\%). AP and lateral spinal radiography showed cement leakage in $29(41.4 \%)$ of the 70 treated vertebral bodies with PVP and ITR. Leakages were into the intervertebral disk $(n=7)$, puncture path $(n=3)$, paravertebral space $(n=5)$ or veins $(n=14)$; none were into the spinal canal.
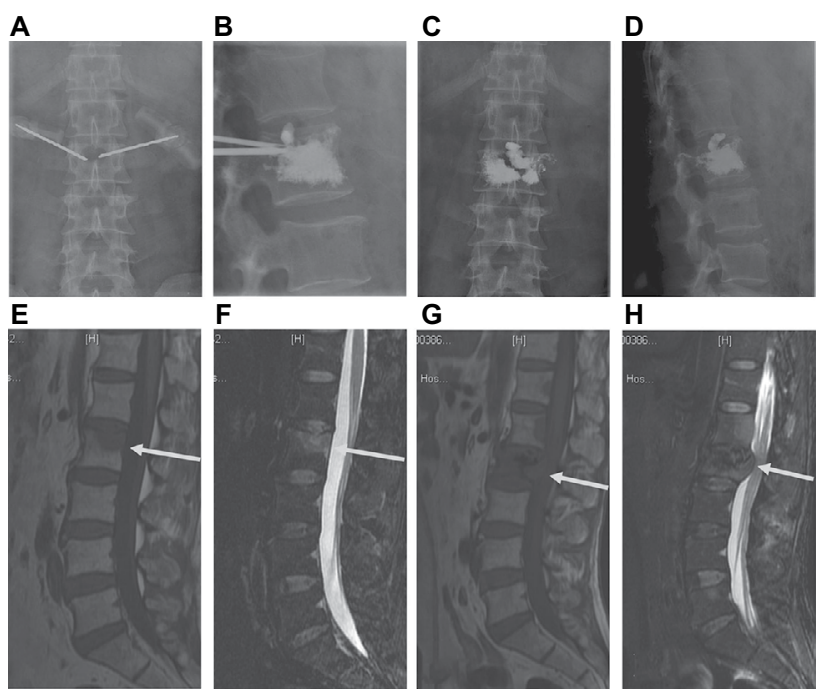

Figure 3 Group B: spinal metastatic tumor with epidural involvement of $L 2$ vertebra owing to metastasis from lung cancer in a 54-year-old male patient with spinal pain prior to the procedure.

Notes: (A) The bone puncture needles are inserted into the L2 vertebra body bilaterally. (B) PMMA is injected into the vertebral body bilaterally through the bone puncture needle. (C, D) The AP and lateral view immediately after the procedures show that the PMMA is injected into the $L 2$ vertebral body with leakage into the paravertebral space and intervertebral disk. (E, F) Sagittal TIWI and T2WI show the malignant spinal tumor of $L 2$ vertebra (arrow) with invasion of the posterior wall prior to the procedure. $(\mathbf{G}, \mathbf{H})$ Sagittal TIWI and T2WI reveal that malignant vertebral compression fracture of the $L 2$ vertebral body and spinal cord compression (arrow) are aggravated with instability of the vertebral body 7 months after PVP.

Abbreviations: AP, anteroposterior; PMMA, polymethyl methacrylate; PVP, percutaneous vertebroplasty; TIWI, TI-weighted image; T2WI, T2-weighted image.

Table I Baseline characteristics of the study populations between the two groups

\begin{tabular}{|c|c|c|c|}
\hline Characteristics & $\begin{array}{l}\text { PVP and ITR } \\
(n=7 I)\end{array}$ & PVP $(n=53)$ & $P$-value \\
\hline Age (years) (mean $\pm S D)$ & $\begin{array}{l}58.17 \pm 8.70 \\
(37-76)\end{array}$ & $\begin{array}{l}59.51 \pm 12.09 \\
(33-90)\end{array}$ & 0.474 \\
\hline Male/female (n) & $40 / 31$ & $31 / 22$ & 0.811 \\
\hline $\begin{array}{l}\text { Duration of } \\
\text { symptoms (weeks) }\end{array}$ & $\begin{array}{l}10.68 \pm 8.33 \\
(1-30)\end{array}$ & $\begin{array}{l}9.11 \pm 6.03 \\
(I-26)\end{array}$ & 0.249 \\
\hline \multicolumn{4}{|l|}{ Primary tumor } \\
\hline Lung cancer & 43 & 29 & \\
\hline Breast cancer & 4 & 5 & \\
\hline Colon cancer & 5 & I & \\
\hline Prostate cancer & 7 & 3 & \\
\hline Thyroid carcinoma & 5 & 6 & \\
\hline Liver cancer & 3 & 3 & \\
\hline Renal cancer & 2 & 1 & \\
\hline Multiple myeloma & 2 & 2 & \\
\hline Gastric cancer & 0 & I & \\
\hline Thymic carcinoma & 0 & I & \\
\hline Pancreatic cancer & 0 & I & \\
\hline \multicolumn{4}{|c|}{ Number of treated vertebrae per patients } \\
\hline 1 & 47 & 27 & \\
\hline 2 & 12 & 10 & \\
\hline 3 & 7 & 10 & \\
\hline 4 & 5 & 6 & \\
\hline
\end{tabular}

Abbreviations: PVP, percutaneous vertebroplasty; ITR, interventional tumor removal. 
Table 2 Initial and follow-up outcomes of the study populations between the two groups

\begin{tabular}{|c|c|c|c|}
\hline Characteristics & $\begin{array}{l}\text { PVP and ITR } \\
(n=7 I)\end{array}$ & PVP $(n=53)$ & $P$-value \\
\hline Technical success, n (\%) & $70(99)$ & $53(100)$ & 0.999 \\
\hline $\begin{array}{l}\text { Initial clinical results } \\
\text { (pain relief), n (\%) }\end{array}$ & $66(94)$ & $39(74)$ & 0.001 \\
\hline $\begin{array}{l}\text { Hospital stay (days), } \\
\text { mean } \pm \text { SD }\end{array}$ & $6.39 \pm 1.08$ & $6.43 \pm 1.01$ & 0.938 \\
\hline Cement leakage, n (\%) & $29(4 I .4)$ & $29(55)$ & 0.144 \\
\hline $\begin{array}{l}\text { Cement filling, } \\
\text { volume }(\mathrm{mL}) \text {, mean } \pm S D \\
\text { (range) }\end{array}$ & $\begin{array}{l}5.62 \pm 1.34 \\
(3-8)\end{array}$ & $\begin{array}{l}5.00 \pm 1.33 \\
(2-8)\end{array}$ & 0.012 \\
\hline $\begin{array}{l}\text { Clinical follow-up } \\
\text { (months), mean } \pm \text { SD }\end{array}$ & $19.0 \pm 7.26$ & $20.02 \pm 8.89$ & 0.486 \\
\hline $\begin{array}{l}\text { Final clinical results } \\
\text { (pain relief), } \mathrm{n}(\%)\end{array}$ & $62(89)$ & $33(62)$ & $<0.001$ \\
\hline $\begin{array}{l}\text { Stability of the treated } \\
\text { vertebrae, } n(\%)\end{array}$ & $65(93)$ & $40(76)$ & 0.007 \\
\hline
\end{tabular}

Abbreviations: PVP, percutaneous vertebroplasty; ITR, interventional tumor removal.

In group B, PVP was technically successful in all patients. AP and lateral spinal radiography showed cement leakage in $29(54.7 \%)$ of the 53 vertebral bodies. Leakages were leaked into the intervertebral disk $(\mathrm{n}=7)$, puncture site $(n=3)$, paravertebral space $(n=7)$ or veins $(n=11)$; cement leaded into the spinal canal in one patient, which resulted in complete paraplegia of the patient.

\section{Pain relief}

Table 2 summarizes the follow-up clinical outcomes between the two groups. In group A, the overall clinical assessment at the last follow-up exhibited excellent pain relief $(n=36)$ and good pain relief $(n=13)$ in 62 patients with a pain relief rate of $88.6 \%(95 \% \mathrm{CI}: 81 \%, 96 \%)$. Four $(5.7 \%)$ of the patients had fair result in pain relief and four $(5.7 \%)$ reported poor pain relief. In 66 patients with excellent or good pain relief at the time of discharge, 62 patients remained resolution or relief of the pain, two patients had pain unchanged and two deteriorated. In four patients without pain relief at the time of discharge, two had pain unchanged and two deteriorated.

In group B, clinical assessment at the final follow-up found complete excellent pain relief $(n=19)$ or good pain relief $(n=14)$ in 33 patients with a pain relief rate of $62.3 \%$ (95\% CI: 49\%, 76\%). In 39 patients with excellent or good pain relief at the time of discharge, 29 patients remained resolution or relief of the pain, eight patients had pain unchanged and two deteriorated. In 14 patients without pain relief at the time of discharge, four patients had good pain relief, four unchanged and six deteriorated.
Deterioration of pain was experienced in eight patients at last follow-up due to progression of the vertebral metastases and compression. The overall excellent and good pain relief rates at the last follow-up were significantly higher in group A than those in group $\mathrm{B}(P<0.001$; Table 2).

\section{Functional outcomes}

There were significant differences in average VAS score, ODI score and KPS at 1, 3 and 6 months, 1 year and $>1$ year between group A and group B $(P<0.05$; Table 3$)$. There were no significant differences in average preoperative VAS score, ODI score and KPS between the two groups.

\section{ASIA impairment scale assessment}

ASIA impairment scale assessment at the last follow-up exhibited ASIA impairment scale E in 50 patients (Figure 1), ASIA impairment scale A in one patient and ASIA impairment scale B-D (incomplete paraplegia) in 19 patients in group A. In 30 patients with ASIA impairment scale A-D, full recovery $(n=10$; Figure 2$)$ and improvement $(n=14)$ of paraplegia were achieved in 24 patients $(80 \%)$. Two of the patients had no change and four had deteriorated in ASIA impairment scale.

Whereas, in group B, ASIA impairment scale assessment at the last follow-up exhibited ASIA impairment scale $\mathrm{E}$ in 22 patients, ASIA impairment scale $\mathrm{A}$ in three patients and ASIA impairment scale B-D in 27 patients. In 25 patients with ASIA impairment scale E prior to PVP, incomplete paraplegia was observed in five patients and no paraplegia in 20 patients. In 28 patients with ASIA impairment scale A-D prior to PVP, full recovery $(\mathrm{n}=2)$ and improvement $(\mathrm{n}=10)$ of paraplegia were achieved in 12 patients (42.9\%). Eight of the patients had no change and eight had deteriorated in ASIA impairment scale (Figure 3). The paraplegia recovery rate in patients with paraplegia in group A was higher than that of patients with paraplegia in group B (80\% vs $42.9 \%$, $P=0.004)$.

\section{Cement filling and stability}

The mean cement filling volume was significantly higher in group A (5.62 $\pm 1.34 \mathrm{~mL}$; range, $3-8 \mathrm{~mL})$ in 70 treated vertebrae than that in 53 treated vertebrae with PVP in group B $(5.00 \pm 1.33 \mathrm{~mL}$; range $2-8 \mathrm{~mL})(P=0.012)$. In addition, five patients experienced further malignant vertebral compression fractures in group A during follow-up, while further malignant vertebral compression fractures were observed in 13 patients in group B. The stability of the involved malignant 
vertebral body in group A was significantly higher than that in group $\mathrm{B}(P=0.007)$.

\section{Discussion}

In most patients with spinal metastasis, the treatment is largely palliative and aims to achieve relief of pain and to regain function, thus improving the quality of life of the patient as quickly as possible. Because of their immunocompromised status from ongoing chemotherapy, poor nutrition and comorbid medical conditions, these patients cannot tolerate the curative surgical methods. In recent years, PVP and percutaneous kyphoplasty (PKP) are emerging as alternatives to treat spinal metastatic disease, ${ }^{1-4,16-19}$ but PVP or PKP have limitations in patients with massive PMMA leakage, destruction of the posterior cortex of the vertebra and malignant vertebral compression fractures.

Compared with PVP, PVP and ITR have the following advantages: 1) control the direction of the cement into the target area, 2) improve the clinical efficacy by removal of the tumor, and 3) increase the amount of PMMA injection to increase the vertebral stability and prevent compression fracture. Although PKP also has the advantages of minimizing cement leakage, reducing vertebral compression, relief pain and increased vertebral height, it has the risk of damaging the posterior wall when the balloon is inflated too high and can aggravate the symptoms of neurological compression in malignant vertebral compression fractures. Therefore, PVP and ITR have not only increased the application of PVP but also provided an attractive option in cases with massive PMMA leakage, destruction of the cortex of the vertebra and malignant vertebral compression fractures.

A very important outcome of PVP and ITR was to regain neurological function caused by malignant vertebral compression fractures. In this study, 24 of $30(80 \%)$ patients with paraplegia prior to PVP and ITR in group A had regained partial $(n=14)$ or complete $(n=10)$ neurological function at the last follow-up, which was much better than the patients who underwent PVP $(42.8 \%, 12 / 28)$ and better than the findings of Shimony et al. ${ }^{20}$ Removal of the malignant tumor by ITR and PVP might be the most important factors for promising results, as these procedures allow shrinkage or elimination of the malignant metastatic vertebral tumor and restore the outline of the spinal cord.

The recent literature on spinal metastases treated with PVP revealed complete or partial pain relief in $73-100 \%$ of the treated patients. . $^{3,4,8,16-18,20-22}$ For example, Cotten et $\mathrm{al}^{3}$ reported a decrease in pain level in $75 \%$ of patients 
at a 6-month follow-up and a complication rate of $8 \%$ in a series of 37 patients with osteolytic metastases and myeloma. Calmels et $\mathrm{al}^{4}$ reported an analgesic efficacy rate of $92 \%$ at 6 months and a complication rate of $12 \%$ in a series of 52 patients with osteoblastic and mixed spinal metastases. Our results of $88.6 \%$ pain relief or pain improvement during follow-up in group A were at the middle end of the reported range of $73-100 \%$ pain relief in patients with spinal metastases. ${ }^{3,4,8,16-18,20-22}$ The promising result indicated that PVP and ITR were an effective approach for pain relief in patients with spinal metastases.

The cement leakage rate following PVP reported in the literature ranges between $11 \%$ and $73 \% .^{3-5,16,19,23}$ The incidence of cement leakage in this study was $41.4 \%$ in patients treated with PVP and ITR, which was in the middle of the reported range of $11-73 \%$ in patients treated with PVP alone. In theory, PVP and ITR may allow cement to be injected directly into the cavity with lower injection pressure, and thus lower the cement leakage rate. However, because the cortex of the vertebra was damaged in patients with malignant vertebral compression fractures and/or spinal metastatic tumor with epidural involvement, it was difficult to prevent cement leakage or reduce the leakage rate.

One limitation of this study was that this is a blind, singlecenter study that may not be widely applicable. Second, the incidence of cement leakage was not obviously decreased by PVP and ITR. Third, the life span of the patients was short, and death due to rapid progression of the disease might have masked both the benefits and the adverse effects of the procedure. Finally, PVP and ITR were very operator dependent, and only experienced radiologists in vertebroplasty could perform the procedures.

\section{Conclusion}

PVP and ITR proved to be an effective approach for patients with malignant vertebral compression fractures and/or spinal metastatic tumor and provided distinct advantages in pain relief, function recovery and vertebral stability that are comparable to that obtained with PVP alone. Although the results are promising, longer follow-up and expanded clinical works are needed.

\section{Acknowledgment}

This work was supported by the Foundation of Shanghai Municipal Commission of Health and Family Planning (grant number: 201440269).

\section{Disclosure}

The authors report no conflicts of interest in this work.

\section{References}

1. Anselmetti GC, Muto M, Guglielmi G, Masala S. Percutaneous vertebroplasty or kyphoplasty. Radiol Clin North Am. 2010;48: 641-649.

2. Jensen ME, Kallmes DE. Percutaneous vertebroplasty in the treatment of malignant spine disease. Cancer J. 2002;8(2):194-206.

3. Cotten A, Dewatre F, Cortet B, et al. Percutaneous vertebroplasty for osteolytic metastases and myeloma: effects of the percentage of lesion filling and the leakage of methylmethacrylate at clinical follow-up. Radiology. 1996;200(2):525-530.

4. Calmels V, Vallée JN, Rose M, Chiras J. Osteoblastic and mixed spinal metastases: evaluation of the analgesic efficacy of percutaneous vertebroplasty. AJNR Am J Neuroradiol. 2007;28(3):570-574.

5. Barragán-Campos HM, Vallée JN, Lo D, et al. Percutaneous vertebroplasty for spinal metastases: complications. Radiology. 2006;238(1): 354-362.

6. Bhatt AD, Schuler JC, Boakye M, Woo SY. Current and emerging concepts in non-invasive and minimally invasive management of spine metastasis. Cancer Treat Rev. 2013;39(2):142-152.

7. Tseng YY, Yang ST, Tu PH, Yang TC, Lo YL. Minimally invasive vertebroplasty in the treatment of pain induced by spinal metastatic tumor Minim Invasive Neurosurg. 2008;51(5):280-284.

8. Chen KY, Ma HI, Chiang YH. Percutaneous transpedicular vertebroplasty with polymethyl methacrylate for pathological fracture of the spine. J Clin Neurosci. 2009;16(10):1300-1304.

9. Ofluoglu O. Minimally invasive management of spinal metastases. Orthop Clin North Am. 2009;40(1):155-168.

10. Anselmetti GC, Manca A, Kanika K, et al. Temperature measurement during polymerization of bone cement in percutaneous vertebroplasty: an in vivo study in humans. Cardiovasc Intervent Radiol. 2009;32(3): 491-498.

11. Quraishi NA, Gokaslan ZL, Boriani S. The surgical management of metastatic epidural compression of the spinal cord. J Bone Joint Surg Br. 2010;92(8):1054-1060.

12. Gu YF, Li YD, Wu CG, Sun ZK, He CJ. Safety and efficacy of percutaneous vertebroplasty and interventional tumor removal for metastatic spinal tumors and malignant vertebral compression fractures. AJR Am J Roentgenol. 2014;202(3):W298-W305.

13. LiY, Gu YF, Sun ZK, et al. Comparison of percutaneous vertebroplasty with and without interventional tumour removal for malignant vertebral compression fractures with symptoms of neurological compression. Eur Radiol. 2013;23(10):2754-2763.

14. Song HM, Gu YF, Li YD, Wu CG, Sun ZK, He CJ. Interventional tumor removal: a new technique for malignant spinal tumor and malignant vertebral compression fractures without epidural involvement. Acta Radiol. 2014;55(8):976-984.

15. American Spinal Injury Association. Reference Manual of the International Standards for Neurological Classification of Spinal Cord Injury. Chicago, III: American Spinal Injury Association; 2003.

16. Fourney DR, Schomer DF, Nader R, et al. Percutaneous vertebroplasty and kyphoplasty for painful vertebral body fractures in cancer patients J Neurosurg. 2003;98(1 suppl):21-30.

17. Weill A, Chiras J, Simon JM, Rose M, Sola-Martinez T, Enkaoua E. Spinal metastases: indications for and results of percutaneous injection of acrylic surgical cement. Radiology. 1996;199(1):241-247.

18. Martin JB, Wetzel SG, Seium Y, et al. Percutaneous vertebroplasty in metastatic disease: transpedicular access and treatment of lysed pedicles- initial experience. Radiology. 2003;229(2):593-597.

19. Saliou G, Kocheida el M, Lehmann P, et al. Percutaneous vertebroplasty for pain management in malignant fractures of the spine with epidural involvement. Radiology. 2010;254(3):882-890. 
20. Shimony JS, Gilula LA, Zeller AJ, Brown DB. Percutaneous vertebroplasty for malignant compression fractures with epidural involvement. Radiology. 2004;232(3):846-853.

21. Alvarez L, Alcaraz M, Pérez-Higueras A, et al. Percutaneous vertebroplasty: functional improvement in patients with osteoporotic compression fractures. Spine (Phila Pa 1976). 2006;31(10):1113-1118.
22. Cortet B, Cotten A, Boutry N, et al. Percutaneous vertebroplasty in patients with osteolytic metastases or multiple myeloma. Rev Rhum Engl Ed. 1997;64(3):177-183.

23. Bròdano GB, Cappuccio M, Gasbarrini A, et al. Vertebroplasty in the treatment of vertebral metastases: clinical cases and review of the literature. Eur Rev Med Pharmacol Sci. 2007;11(2):91-100.

\section{Publish your work in this journal}

The Journal of Pain Research is an international, peer reviewed, open access, online journal that welcomes laboratory and clinical findings in the fields of pain research and the prevention and management of pain. Original research, reviews, symposium reports, hypothesis formation and commentaries are all considered for publication.
Dovepress

The manuscript management system is completely online and includes a very quick and fair peer-review system, which is all easy to use. Visit http://www.dovepress.com/testimonials.php to read real quotes from published authors. 